\title{
Gestational Dexamethasone Treatment Elicits Sex-Dependent Alterations in Locomotor Activity, Reward-Based Memory and Hippocampal Cholinergic Function in Adolescent and Adult Rats
}

\author{
Marisa L Kreider', Edward D Levin ',2, Frederic J Seidler' and Theodore A Slotkin, ${ }^{*, 2}$ \\ 'Department of Pharmacology and Cancer Biology, Duke University Medical Center, Durham, NC, USA; '2Department of Psychiatry and \\ Behavioral Sciences, Duke University Medical Center, Durham, NC, USA
}

\begin{abstract}
Glucocorticoids are the consensus treatment for preventing respiratory distress syndrome in preterm infants but there is emerging evidence of subsequent neurobehavioral abnormalities, independent of somatic growth effects. Pregnant rats were given $0.2 \mathrm{mg} / \mathrm{kg}$ of dexamethasone, a dose commensurate with clinical use, on gestational days 17-19 and behavioral evaluations were made on the offspring in adolescence and adulthood. The dexamethasone groups had the same body weights as the controls but nevertheless displayed long-term, sex-selective alterations in locomotor and cognitive behaviors. In the figure-8 activity apparatus, dexamethasone treatment ablated the normal sex differences in locomotor activity by reducing values in females to the lower level typical of males; habituation of activity similarly was impaired in females, reducing the profile to match that of control males, while male rats in the dexamethasone group showed a partially feminized pattern of habituation. In the 8-arm radial maze, control rats displayed typical sex differences, with male rats performing more accurately than females. Dexamethasone treatment eliminated this normal dichotomy, delaying learning in males while improving performance in females to the level normally seen in control males. Finally, we assessed hippocampal $\left[{ }^{3} \mathrm{H}\right]$ hemicholinium-3 binding as a biomarker for cholinergic synaptic activity, and again found loss of sex differences in the dexamethasone group: values in males were increased to the higher levels typical of females. These results indicate that gestational treatment with dexamethasone obtunds the normal sex differences in neurochemistry and behavior that are typically seen in adolescence in adulthood, thus producing sex-selective alterations in activity, learning, and memory.
\end{abstract}

Neuropsychopharmacology (2005) 30, 1617-1623. doi: |0.1038/sj.npp.13007|6; published online 6 April 2005

Keywords: acetylcholine systems; antenatal steroids; brain development; dexamethasone; hemicholinium-3 binding; hippocampus; preterm delivery

\section{INTRODUCTION}

Since the release of the NIH Consensus Report over a decade ago (Gilstrap et al, 1994), synthetic glucocorticoids have been routinely administered to prevent respiratory distress in preterm infants, currently utilized in $10 \%$ of all US pregnancies (Matthews et al, 2002). Although the original recommendation was for a single course of glucocorticoid treatment, a recent study showed that $85 \%$ of clinical use actually involves repeated courses (Dammann

\footnotetext{
* Correspondence: Dr TA Slotkin, Department of Pharmacology \& Cancer Biology, Duke University Medical Center, Box 3813, Room Cl62, LSRC Building, Research Drive, Durham, NC 277। 0, USA, Tel: + |91968I 8015, Fax: + I9196848197, E-mail: t.slotkin@duke.edu Received 5 January 2005; revised 3 February 2005; accepted 4 February 2005

Online publication: I0 February 2005 at http://www.acnp.org/citations/ NPP02 $1005050004 /$ default.pdf
}

and Matthews, 2001) and specific recommendations for prolonged or repeated use are beginning to emerge (Crowther and Harding, 2003), with some treatments over a period of several weeks (Crowther and Harding, 2003; Dammann and Matthews, 2001; Jobe, 2000). High doses of glucocorticoids, sufficient to elicit clear-cut growth retardation, are commonly given in refractory cases, despite an emerging suspicion that there might be long-term adverse consequences (Bakker et al, 2001; Finer et al, 2000; Jobe, 2000). Indeed, recent epidemiologic studies indicate an elevated risk of metabolic disorders, cardiovascular disease, and cognitive deficits after glucocorticoid use in preterm delivery (Barrington, 2001; Seckl, 2001; Shinwell et al, 2000; Trautman et al, 1995; Yeh et al, 2004).

Given the confounds in outcome assessments after preterm delivery, animal models are essential to establish both cause-and-effect relationships for the adverse effects of glucocorticoids and to evaluate whether neurobehavioral 
deficits occur at clinically relevant doses and particularly with exposures that do not produce lasting somatic growth impairment. Unfortunately, the vast majority of studies on developmental effects of glucocorticoids concentrate on regimens and doses that lie well above those used in preterm labor, resulting in frank somatic effects and endocrine disruption (Bohn, 1984; Fuxe et al, 1994, 1996; Gilad et al, 1998; Gould et al, 1997; Maccari et al, 2003; Matthews, 2000; Matthews et al, 2002; McEwen, 1992; Meaney et al, 1996; Weinstock, 2001; Welberg and Seckl, 2001). Accordingly, studies have reported both increases and decreases in locomotor and other general activities, likely a reflection of different dosing paradigms with varying degrees of persistent somatic growth impairment (Benesová and Pavlík, 1989; Ferguson and Holson, 1999; Flagel et al, 2002; Neal et al, 2004). Nevertheless, neonatal rats exposed to dexamethasone also display impaired spatial learning (Kamphuis et al, 2003) as well as alterations in social behaviors (Kamphuis et al, 2004) and complex motor skills (Benesová and Pavlík, 1989) at doses simulating those used clinically.

In the current study, we explored the consequences of gestational dexamethasone treatment in rats, utilizing a dose $(0.2 \mathrm{mg} / \mathrm{kg})$ well within the clinically used range. Despite the absence of somatic growth impairment, we found sex-selective alterations in activity and cognitive performance in adolescence and adulthood. In addition, we conducted preliminary investigations of the synaptic mechanisms underlying the behavioral defects, focusing on the role of cholinergic innervation of the hippocampus in learning and memory, a likely target for developmental exposure to glucocorticoids (Takahashi and Goh, 1998; Zahalka et al, 1993b). We measured binding of $\left[{ }^{3} \mathrm{H}\right]$ hemicholinium-3 (HC3) to the high-affinity presynaptic choline transporter, the protein that is rate-limiting in acetylcholine biosynthesis and whose expression changes in direct response to persistent increases or decreases in nerve impulse activity (Klemm and Kuhar, 1979; Simon et al, 1976); these assessments were modeled after the use of HC3 binding to characterize changes in cholinergic synaptic function elicited by developmental neurotoxicants (Aubert et al, 1996; Happe and Murrin, 1992; Navarro et al, 1989; Qiao et al, 2003; Slotkin et al, 1990; Zahalka et al, 1992, 1993a).

\section{METHODS}

\section{Animal Treatments}

All studies were performed in accordance with the Declaration of Helsinki and with the Guide for the Care and Use of Laboratory Animals as adopted and promulgated by the National Institutes of Health. Timed-pregnant Sprague-Dawley rats (Charles River Laboratories, Raleigh, NC) were housed individually and given free access to food and water. On gestational days 17, 18, and 19, dams were administered $0.2 \mathrm{mg} / \mathrm{kg}$, subcutaneous (s.c.), of dexamethasone phosphate (Sigma Chemical Co., St Louis, MO), while controls received equivalent volumes of isotonic saline $(1 \mathrm{ml} / \mathrm{kg})$. At birth, pups were randomized and redistributed to the nursing dams within their respective treatment groups with litter sizes maintained at 10 pups. To distribute any maternal caretaking differences equally among all pups, randomization within treatment groups was carried out every 4 days until weaning on postnatal day (PN) 21 , at which point the day-night cycle was reversed (lights on at $1800 \mathrm{~h}$ ).

All behavioral testing was carried out during the dark phase, the most active period, but in a lighted environment so that the rats could access the visual cues necessary to perform the tasks. Tests were performed on 8-9 rats per sex per treatment group, utilizing no more than one male and one female from each litter. Behavioral assessments were begun with the figure-8 apparatus on PN31, 32, and 33, followed by the radial arm maze beginning on PN45 and continuing through PN68. This sequence was designed to permit multiple behavioral tests to be conducted without significant carry-over of effects from one test to the next (Icenogle et al, 2004; Levin et al, 2001, 2002; Slotkin et al, 1999). Tests were scored by a trained observer who was blinded to the animal treatments.

\section{Figure-8 Activity}

The apparatus, in the shape of a figure- 8 , consisted of a continuous, enclosed $10 \times 10 \mathrm{~cm}$ alley, $70 \mathrm{~cm}$ long and $42 \mathrm{~cm}$ wide, with a $21 \times 16 \mathrm{~cm}$ central arena, a $20 \mathrm{~cm}$-high ceiling and two blind alleys extending $20 \mathrm{~cm}$ from either side. Data for locomotor activity were acquired with eight photobeams, one located on each of the two blind alleys and three on each of the two loops of the Figure-8, crossing the alleys. Three 1-h sessions were evaluated on PN31, 32, and 33, with each session divided into twelve 5-min blocks. Overall activity was determined as the average number of beam breaks per block and habituation was evaluated as the linear trend for the decline in activity over the sequential blocks within each session (Crofton et al, 1991; Keppel, 1982; Levin et al, 2001, 2002).

\section{Eight-Arm Radial Maze}

Over the period of training and testing, animals had free access to water but food was restricted to approximately $15 \mathrm{~g} /$ day so as to provide an adequate stimulus to seek the food reward obtained in the maze. The maze, elevated $30 \mathrm{~cm}$ from the floor, consisted of a central platform $50 \mathrm{~cm}$ in diameter, with eight $10 \times 60 \mathrm{~cm}$ arms projecting radially, each with a food cup $2 \mathrm{~cm}$ from the distal end. Tests were conducted in a quiet room with multiple extra-maze visual cues that always remained in the same locations relative to the maze. The rats were first familiarized with the food reinforcement by placing each rat in an opaque, plastic cylinder in the middle of the maze with a sugar-coated cereal (Froot Loops ${ }^{\circledR}$ halves), giving them up to $5 \mathrm{~min}$ to eat all the pieces. Subsequently, the rats were tested for 12 sessions conducted from PN45 to PN68. In each session, the arms were baited and the rat placed in the opaque cylinder on the central platform for $10 \mathrm{~s}$. The session started when the cylinder was removed, and the rat was allowed free access to the arms. Recordings were made of arm choices, a single choice being recorded once the rat placed all of its paws past the threshold of the arm. Errors were defined as subsequent entries into a previously entered arm and presented as 'entries to repeat,' the number of arms entered 
prior to reentry into an arm in which the bait had already been consumed (Icenogle et al, 2004; Levin et al, 2001, 2002). Each session lasted until the rat entered all eight arms at least once, or for a maximum of $5 \mathrm{~min}$; in order for a session to be counted, the rat had to have made a reentry, finished the maze perfectly or entered at least five arms. The response latency (time per entry) was calculated by dividing the total time of the session by the number of arms entered. Data for both entries to repeat and latency were compiled as results averaged from sequential pairs of sessions to obviate variability within individual sessions (Icenogle et al, 2004; Levin et al, 2001, 2002).

\section{HC3 Binding}

Littermates (six animals per sex for each treatment with no more than one male and one female used from each litter) of the animals used for behavioral assessments were decapitated on PN75 and the hippocampus was rapidly dissected, frozen with liquid nitrogen and maintained at $-45^{\circ} \mathrm{C}$ until assayed. Tissues were thawed in 79 volumes of ice-cold $10 \mathrm{mM}$ sodium-potassium phosphate buffer $(\mathrm{pH}$ 7.4), homogenized with a Polytron (Brinkmann Instruments, Westbury, NY), and sedimented at $40000 \mathrm{~g}$ for $15 \mathrm{~min}$. The membrane pellet was resuspended (Polytron) in the original volume of buffer, resedimented, and the resultant pellet was resuspended using a smooth glass homogenizer fitted with a Teflon pestle, in $10 \mathrm{mM}$ sodiumpotassium phosphate buffer ( $\mathrm{pH} 7.4$ ) and $150 \mathrm{mM} \mathrm{NaCl}$. Radioligand binding was evaluated (Vickroy et al, 1984) with $2 \mathrm{nM}\left[{ }^{3} \mathrm{H}\right] \mathrm{HC} 3$ (specific activity $161 \mathrm{Ci} / \mathrm{mmol}$; PerkinElmer Life Sciences, Boston, MA), with incubation for $20 \mathrm{~min}$ at room temperature, followed by rapid vacuum filtration onto glass fiber filters (presoaked for $30 \mathrm{~min}$ with $0.1 \%$ polyethyleneimine in buffer). The nonspecific component was defined as radioligand binding in the presence of $10 \mu \mathrm{M}$ unlabeled HC3 (Sigma). Binding values were expressed relative to membrane protein (Smith et al, 1985). The selection of a single concentration of radioligand for the binding analysis enables the detection of changes in either binding affinity or capacity but does not permit distinction between effects on the two parameters. This strategy was necessitated by limitations in the amount of tissue available from each animal. However, the interpretation of results of the present study, which relate to HC3 binding as an index of neural activity, is valid for changes in either parameter (Aubert et al, 1996; Happe and Murrin, 1992; Navarro et al, 1989; Qiao et al, 2003; Slotkin et al, 1990; Zahalka et al, 1992, 1993a).

\section{Data Analysis}

Data are presented as means and standard errors. Treatment-related differences were evaluated with analysis of variance (ANOVA) incorporating all factors in an initial, global test: treatment, sex, and where appropriate to each behavior, session and block. Lower-order ANOVAs were then carried out where appropriate, as dictated by the interaction of treatment with the other variables. Significance for main effects was assumed at $p<0.05$; however, for interactions at $p<0.1$, we also examined whether lower- order main effects were detectable after subdivision of the interactive variables (Snedecor and Cochran, 1967).

\section{RESULTS}

Dexamethasone had no significant effect on maternal weight gain during pregnancy, the proportion of dams giving birth, litter size, and viability, or the proportion of males and females in each litter (data not shown). On PN30, at the commencement of behavioral testing, there were no differences in body weights between the control and dexamethasone-treated groups. Control males weighed $104 \pm 3 \mathrm{~g}$, compared to $106 \pm 3 \mathrm{~g}$ in the dexamethasone group; values in females were $98 \pm 1$ and $95 \pm 3$, respectively.

As found in earlier studies (Levin et al, 2001, 2002; Marmendal et al, 2004; Moraes et al, 2004), control rats showed marked sex differences in activity (Figure 1a) and habituation (Figure 1b) in the figure- 8 apparatus. Males
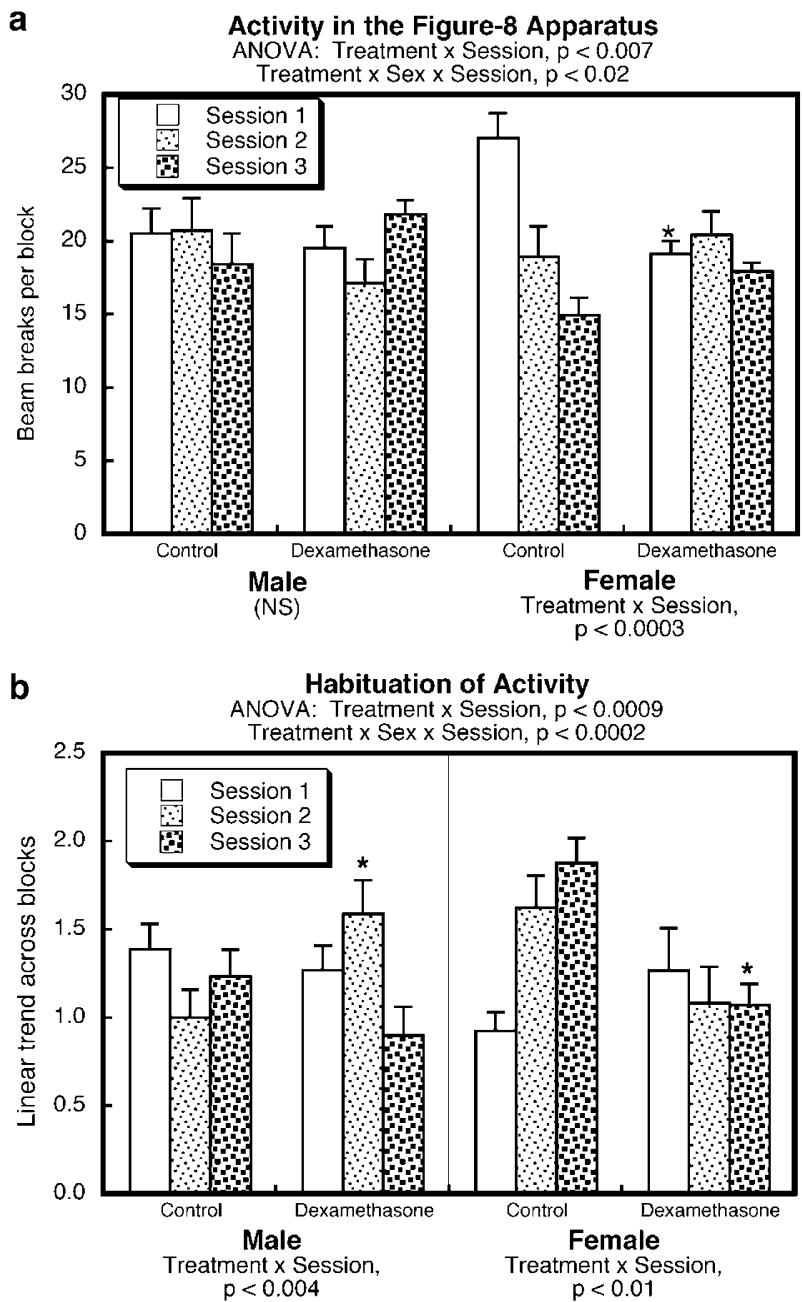

Figure I Effects of dexamethasone on activity (a) and habituation (b) in the figure-8 apparatus. ANOVA across treatments, sexes, and sessions appears at the top of each panel. As e result of the interaction of treatment with sex, data were separated for males and females, and lower-order ANOVAs were then conducted as shown at the bottom of each panel. Asterisks denote the individual values for which the dexamethasone groups differ from the corresponding controls. NS = not significant. 
showed no change in activity over the three sessions but females showed much higher initial activity and a progressive decline over the subsequent sessions $(p<0.004$ for the main effect of sex in the control group). A similar sex difference was seen for habituation: control males showed no significant change over sessions whereas females exhibited a marked increase in the rapidity of habituation $(p<0.009)$. Prenatal dexamethasone treatment completely ablated the sex difference in activity (no significant difference between males and females in the dexamethasone group) by masculinizing the pattern in females. Dexamethasone had similar effects on habituation, converting the pattern in the treated females to match that ordinarily seen in control males, that is, no differences in habituation over successive test sessions. In the males, dexamethasone produced partial feminization, with an increase in activity

a

a Eight-Arm Radial Maze Learning

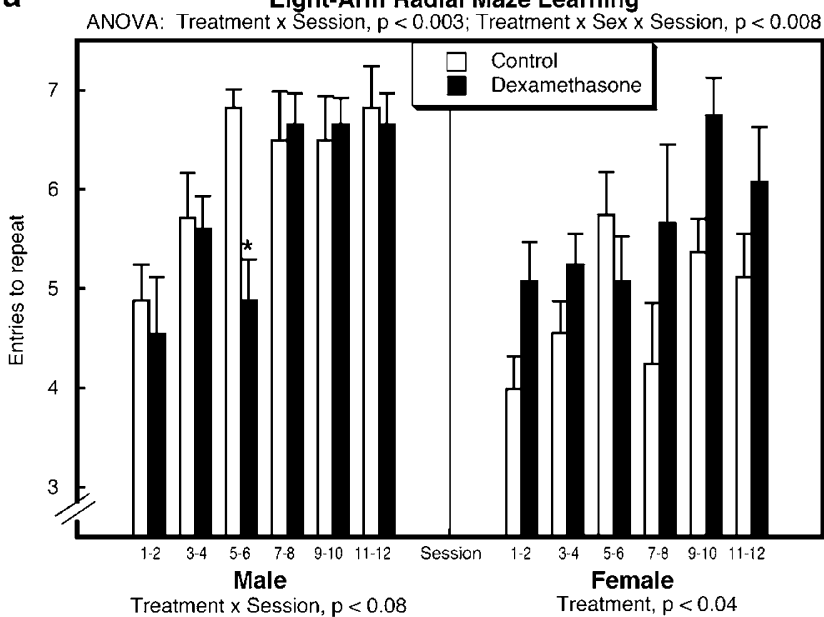

b

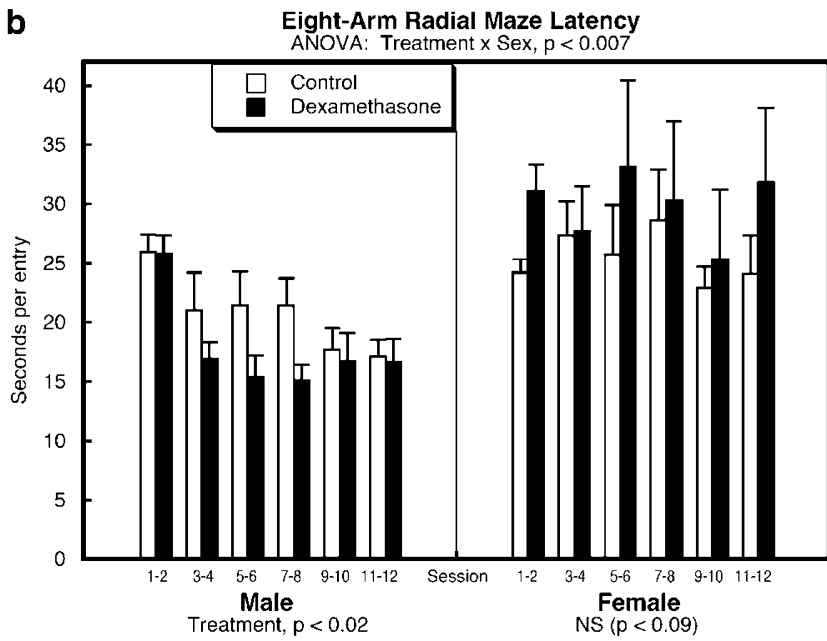

Figure 2 Effects of dexamethasone on entries to repeat (a) and latency (b) in the eight-arm radial maze. ANOVA across treatments, sexes, and sessions appears at the top of each panel. As a result of the interaction of treatment with sex, data were separated for males and females and lowerorder ANOVAs were then conducted as shown at the bottom of each panel. Asterisk denotes the individual male value for entries to repeat, for which the dexamethasone group differs from the corresponding controls; for females, only the main treatment effect was evaluated because of the absence of a treatment $x$ session interaction. Similarly, only main treatment effects appear for latency. NS = not significant. during the second session $(p<0.0002$ for the main effect of session in the dexamethasone group).

In the eight-arm radial maze, control males performed better than females, making fewer re-entries and thus exhibiting a higher value for entries to repeat (Figure $2 \mathrm{a}$; $p<0.0001$ for the main effect of sex). Again, this replicated established, normal sex differences in behavior (Levin et al, $2001,2002)$. Both sexes showed significant improvement over the 12 training sessions ( $p<0.008$ for the main effect of session in males, $p<0.05$ in females). Dexamethasone treatment had opposing effects on performance in the two sexes, slowing the learning in males, while masculinizing performance in females by evoking an overall increase in entries to repeat. Accordingly, unlike the controls, there was no significant sex difference in the animals treated with dexamethasone. The sex-selective effects on learning did not reflect underlying changes in locomotor activity in the maze, as shown by measurements of latency (Figure $2 b$ ). In controls, males showed higher overall activity than females as evidenced by lower latency ( $p<0.004$ for the main effect of sex) and this difference was still fully evident in the dexamethasone-treated group $(p<0.0001)$. In males, dexamethasone elicited a significant overall reduction in latency whereas females tended toward an increase.

Sex differences were also apparent for HC3 binding to membranes prepared from the hippocampus on PN75 (Figure 3). In controls, females displayed significantly higher values than males $(p<0.0007)$. Dexamethasone treatment increased HC3 binding in males to achieve levels indistinguishable from those in females without eliciting a corresponding change in females. Accordingly, after prenatal dexamethasone treatment, there was no longer any sex difference.

\section{DISCUSSION}

The results of the current study indicate that dexamethasone, in a dose commensurate with its use in preterm labor,

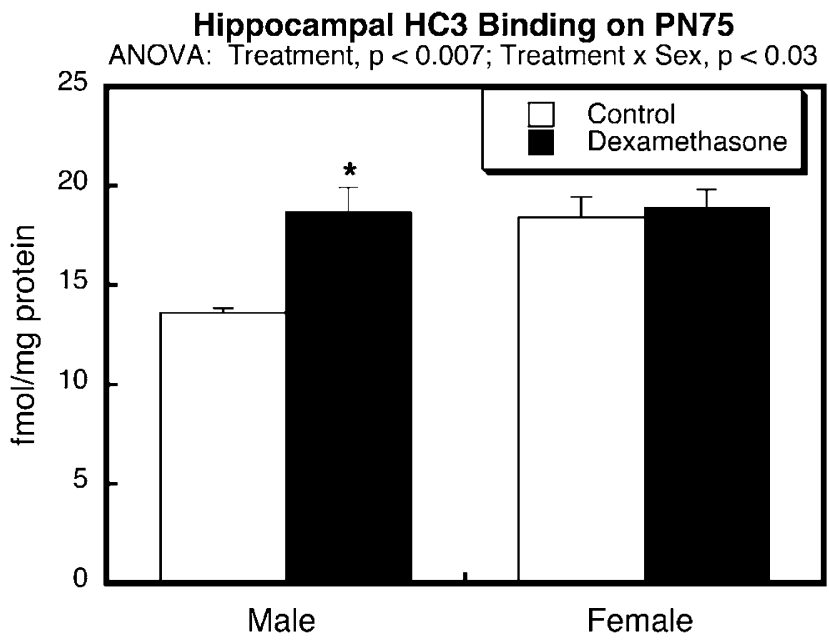

Figure 3 Effects of dexamethasone on $\mathrm{HC} 3$ binding in membrane preparations from the hippocampus. ANOVA across treatments and sexes appears at the top of the panel and, because of the interaction of treatment $\times$ sex, significance was analyzed separated for males and females, with the asterisk denoting the significant difference in males. 
and in the absence of persistent somatic growth inhibition, elicits long-term behavioral alterations in conjunction with changes in hippocampal synaptic function. Sex selectivity is by far the most prominent feature of these effects, with distinctly different outcomes for males and females. Thus, in the Figure-8 apparatus, locomotor activity and habituation were reduced in females but not males and in fact, the latter showed increases in habituation. In the eight-arm radial maze, only the males displayed cognitive impairment as evidenced by a slowing of learning, whereas females actually showed improved performance; similarly, males and females showed changes in opposite directions for latency. Our results thus point to the importance of evaluating sex-dependence of the long-term effects of prenatal dexamethasone exposure, rather than conglomerate assessments of both sexes or, as in many studies, evaluation of effects only in male offspring.

Earlier studies identified effects on behavior and hypothalamo-pituitary-adrenal axis function in male offspring after developmental exposure to higher doses or longer durations of glucocorticoid treatment, regimens that elicit persistent growth retardation (Dean et al, 2001; Holson et al, 1995; Machhor et al, 2004). Similarly, prolonged prenatal stress and the associated release of endogenous maternal glucocorticoids are known to feminize behavioral responses in male rats (Holson et al, 1995; Ward, 1972). Our results, however, indicate that effects involve both sexes and occur at a lower threshold than for persistent growth deficits. There are two important ramifications of these findings. First, the presence or absence of somatic effects is not an adequate predictor of whether a given regimen of antenatal glucocorticoids will spare brain development or behavior. More importantly, though, we found partial masculinization of behavioral performance in females, and feminization of performance in males, so that by and large, the normal sex differences disappeared in the dexamethasone-exposed animals. Interestingly, the same interference with expression of sexually dimorphic behaviors was recently reported for prenatal stress, which also elevates maternal glucocorticoid levels (Bowman et al, 2004). The elimination of sex differences thus points to an underlying mechanism, namely interference with sexual differentiation of the brain, which reaches a peak stage during the period of dexamethasone exposure used here (MacLusky and Naftolin, 1981; MacLusky et al, 1985; McCarthy, 1994), rather than interference targeted singly to androgen or estrogen-related factors, although certainly the differential expression of estrogen receptors in sexually dimorphic areas such as the hippocampus is likely to play a significant role (Kawata et al, 1998). In keeping with this interpretation, prenatal stress or glucocorticoid administration, albeit with growth-retarding regimens, has been found to eliminate sex differences in aromatase activity and in brain morphology (Reznikov et al, 1999, 2004). Accordingly, although much less attention has been paid to outcomes in female offspring, the present results indicate that they are equally likely to show longterm anomalies, albeit with a different, and even opposite, spectrum of effects from those seen in males. Indeed, some of the effects of antenatal glucocorticoids may then resemble those of environmental estrogens, which are known to alter cognitive performance and motor activity in females (Golub et al, 2004; Masuo et al, 2004). The pattern seen here, negation of sex differences, mimics that seen with chlorpyrifos, an organophosphorus insecticide completely unrelated to dexamethasone, but that similarly interferes with sexual differentiation of the brain (Levin et al, 2001, 2002; Slotkin, 2005).

Finally, we determined whether prenatal dexamethasone exposure similarly negates sex differences in neurotransmitter pathways known to be involved in spatial learning, focusing on the hippocampus, in which glucocorticoid receptor expression is prominent in late gestation (Levitt et al, 1996; Speirs et al, 2004), and in which cholinergic projections play a key role (Levin et al, 2001, 2002). Using HC3 binding as a biomarker for cholinergic synaptic activity, we found feminization in males. However, given an underlying mechanism of interference with sexual differentiation of the brain, there is no reason to expect that this is the only brain region or neurotransmitter affected by prenatal dexamethasone treatment, or that only males are targeted. Indeed, prenatal stress eliminates sex differences in monoamine levels (Reznikov and Nosenko, 1996), so it is likely that dexamethasone treatment will have similar actions for these pathways. A detailed neurochemical survey of different brain regions and neurotransmitter systems will be forthcoming in a separate study.

There is growing concern about the long-term sequelae after dexamethasone therapy in preterm infants. Our results support the idea that the beneficial effects on birth outcomes come at a long-term cost of disrupted neurodevelopment, even at doses at or below those in clinical use, and below the threshold for persistent growth deficits. Further, the present findings point to underlying mechanisms for these effects and, equally important, the need to evaluate sex differences in outcomes.

\section{ACKNOWLEDGEMENTS}

This work was supported by USPHS HD09713. We thank Laura Icenogle for technical assistance.

\section{REFERENCES}

Aubert I, Cecyre D, Gauthier S, Quirion R (1996). Comparative ontogenic profile of cholinergic markers, including nicotinic and muscarinic receptors, in the rat brain. J Comp Neurol 369: 31-55.

Bakker JM, van Bel F, Heijnen CJ (2001). Neonatal glucocorticoids and the developing brain: short-term treatment with life-long consequences? Trends Neurosci 24: 649-653.

Barrington KJ (2001). The adverse neuro-developmental effects of postnatal steroids in the preterm infant: a systematic review of RCTs. BMC Pediatr 1: 1-9.

Benesová O, Pavlík A (1989). Perinatal treatment with glucocorticoids and the risk of maldevelopment of the brain. Neuropharmacology 28: 89-97.

Bohn MC (1984). Glucocorticoid induced teratologies of the nervous system. In: Yanai J (ed). Neurobehavioral Teratology. Elsevier: Amsterdam. pp 365-387.

Bowman RE, MacLusky NJ, Sarmiento Y, Frankfurt M, Gordon M, Luine VN (2004). Sexually dimorphic effects of prenatal stress on cognition, hormonal responses, and central neurotransmitters. Endocrinology 145: 3778-3787.

Crofton KM, Howard JL, Moser VC, Gill MW, Reiter LW, Tilson HA et al (1991). Interlaboratory comparisons of motor activity 
experiments: Implications for neurotoxicological assessments. Neurotoxicol Teratol 13: 599-609.

Crowther CA, Harding J (2003). Repeat doses of prenatal corticosteroids for women at risk of preterm birth for preventing neonatal respiratory disease. Cochrane Database Systemat Rev 1: CD003935.

Dammann O, Matthews SG (2001). Repeated antenatal glucocorticoid exposure and the developing brain. Pediatr Res 50: 563-564.

Dean F, Yu C, Lingas RI, Matthews SG (2001). Prenatal glucocorticoid modifies hypothalamo-pituitary-adrenal regulation in prepubertal guinea pigs. Neuroendocrinology 73: 194-202.

Ferguson SA, Holson RR (1999). Neonatal dexamethasone on day 7 causes mild hyperactivity and cerebellar stunting. Neurotoxicol Teratol 21: 71-76.

Finer NN, Craft A, Vaucher YE, Clark RH, Sola A (2000). Postnatal steroids: short-term gain, long-term pain? J Pediatr 137: 9-13.

Flagel SB, Vazquez DM, Watson SJ, Neal CR (2002). Effects of tapering neonatal dexamethasone on rat growth, neurodevelopment, and stress response. Am J Physiol 282: R55-R63.

Fuxe K, Cintra A, Chadi G, Gustafsson JA, Agnati LF (1994). Central glucocorticoid receptors and neuronal plasticity. Methods Neurosci 22: 372-382.

Fuxe K, Diaz R, Cintra A, Bhatnagar M, Tinner B, Gustafsson JA et al (1996). On the role of glucocorticoid receptors in brain plasticity. Cell Mol Neurobiol 16: 239-258.

Gilad GM, Gilad VH, Eliyayev Y, Rabey JM (1998). Developmental regulation of the brain polyamine-stress-response. Int $J$ Dev Neurosci 16: 271-278.

Gilstrap LC, Christensen R, Clewell WH, D'Alton ME, Davidson EC, Escobedo MB et al (1994). Effect of corticosteroids for fetal maturation on perinatal outcomes. J Am Med Assoc 273: 413-418.

Golub MS, Hogrefe CE, Germann SL, Jerome CP (2004). Endocrine disruption and cognitive function in adolescent female rhesus monkeys. Neurotoxicol Teratol 26: 799-809.

Gould E, Tanapat P, McEwen BS (1997). Activation of the type 2 adrenal steroid receptor can rescue granule cells from death during development. Dev Brain Res 101: 265-268.

Happe HK, Murrin LC (1992). High-affinity choline transport regulation by drug administration during postnatal development. J Neurochem 58: 2053-2059.

Holson RR, Gough B, Sullivan P, Badger T, Sheehan DM (1995). Prenatal dexamethasone or stress but not ACTH or corticosterone alter sexual behavior in male rats. Neurotoxicol Teratol 17: 393-401.

Icenogle LM, Christopher C, Blackwelder WP, Caldwell DP, Qiao $\mathrm{D}$, Seidler FJ et al (2004). Behavioral alterations in adolescent and adult rats caused by a brief subtoxic exposure to chlorpyrifos during neurulation. Neurotoxicol Teratol 26: 95-101.

Jobe AH (2000). Glucocorticoids in perinatal medicine: misguided rockets? J Pediatr 137: 1-3.

Kamphuis PJ, Gardoni F, Kamal A, Croiset G, Bakker JM, Cattabeni $\mathrm{F}$ et al (2003). Long-lasting effects of neonatal dexamethasone treatment on spatial learning and hippocampal synaptic plasticity: involvement of the NMDA receptor complex. FASEB J 17: 911-913.

Kamphuis PJGH, Croiset G, Bakker JM, van Bel F, van Ree JM, Wiegant VM (2004). Neonatal dexamethasone treatment affects social behaviour of rats in later life. Neuropharmacology 47: 461-474.

Kawata M, Yuri K, Ozawa H, Nishi M, Ito T, Hu Z et al (1998). Steroid hormones and their receptors in the brain. J Steroid Biochem Mol Biol 65: 273-280.

Keppel G (1982). Design and Analysis: A Researcher's Handbook. Prentice-Hall: Englewood Cliffs, NJ, 699pp.
Klemm N, Kuhar MJ (1979). Post-mortem changes in high affinity choline uptake. J Neurochem 32: 1487-1494.

Levin ED, Addy N, Baruah A, Elias A, Christopher NC, Seidler FJ et al (2002). Prenatal chlorpyrifos exposure in rats causes persistent behavioral alterations. Neurotoxicol Teratol 24: 733-741.

Levin ED, Addy N, Christopher NC, Seidler FJ, Slotkin TA (2001). Persistent behavioral consequences of neonatal chlorpyrifos exposure in rats. Dev Brain Res 130: 83-89.

Levitt NS, Lindsay RS, Holmes MC, Seckl JR (1996). Dexamethasone in the last week of pregnancy attenuates hippocampal glucocorticoid receptor gene expression and elevates blood pressure in the adult offspring in the rat. Neuroendocrinology 64 412-418.

Maccari S, Darnaudery M, Morley-Fletcher S, Zuena AR, Cinque C, Van Reeth O (2003). Prenatal stress and long-term consequences: implications of glucocorticoid hormones. Neurosci Biobehav Rev 27: 119-127.

Machhor N, Balaji T, Raju TN (2004). Postnatal dexamethasone and long term learning and memory functions in developing rats: effect of postnatal age and gender. Life Sci 74: 1925-1935.

MacLusky NJ, Naftolin F (1981). Sexual differentiation of the central nervous system. Science 211: 1294-1302.

MacLusky NJ, Philip A, Hurlburt C, Naftolin F (1985). Estrogen formation in the developing rat brain: sex differences in aromatase activity during early postnatal life. Psychoneuroendocrinology 10: 355-361.

Marmendal M, Roman E, Eriksson CJ, Nylander I, Fahlke C (2004). Maternal separation alters maternal care, but has minor effects on behavior and brain opioid peptides in adult offspring. Dev, Psychobiol 45: 140-152.

Masuo Y, Ishido M, Morita M, Oka S (2004). Effects of neonatal treatment with 6-hydroxydopamine and endocrine disruptors on motor activity and gene expression in rats. Neural Plasticity 11: 59-76.

Matthews SG (2000). Antenatal glucocorticoids and programming of the developing CNS. Pediatr Res 47: 291-300.

Matthews SG, Owen D, Banjanin S, Andrews MH (2002). Glucocorticoids, hypothalamo-pituitary-adrenal (HPA) development, and life after birth. Endocr Res 28: 709-718.

McCarthy MM (1994). Molecular aspects of sexual differentiation of the rodent brain. Psychoneuroendocrinology 19: 415-427.

McEwen BS (1992). Steroid hormones: effect on brain development and function. Hormone Res 37: 1-10.

Meaney MJ, Diorio J, Francis D, Widdowson J, LaPlante P, Caldji C et al (1996). Early environmental regulation of forebrain glucocorticoid receptor gene expression: implications for adrenocortical responses to stress. Dev Neurosci 18: 49-72.

Moraes AP, Schwarz A, Spinosa HS, Florio JC, Bernardi MM (2004). Maternal exposure to diphenhydramine during the fetal period in rats: effects on physical and neurobehavioral development and on neurochemical parameters. Neurotoxicol Teratol 26: 681-692.

Navarro HA, Seidler FJ, Eylers JP, Baker FE, Dobbins SS, Lappi SE et al (1989). Effects of prenatal nicotine exposure on development of central and peripheral cholinergic neurotransmitter systems. Evidence for cholinergic trophic influences in developing brain. J Pharmacol Exp Ther 251: 894-900.

Neal Jr CR, Weidemann G, Kabbaj M, Vazquez DM (2004). Effect of neonatal dexamethasone exposure on growth and neurological development in the adult rat. Am J Physiol 287: R375-R385.

Qiao D, Seidler FJ, Tate CA, Cousins MM, Slotkin TA (2003). Fetal chlorpyrifos exposure: adverse effects on brain cell development and cholinergic biomarkers emerge postnatally and continue into adolescence and adulthood. Environ Health Perspect 111: 536-544. 
Reznikov AG, Nosenko ND (1996). Early postnatal changes in sexual dimorphism of catecholamine and indoleamine content in the brain of prenatally stressed rats. Neuroscience 70: 547-551.

Reznikov AG, Nosenko ND, Tarasenko LV (1999). Prenatal stress and glucocorticoid effects on the developing gender-related brain. J Steroid Biochem Mol Biol 69: 109-115.

Reznikov AG, Nosenko ND, Tarasenko LV (2004). Early postnatal effects of prenatal exposure to glucocorticoids on testosterone metabolism and biogenic monoamines in discrete neuroendocrine regions of the rat brain. Comp Biochem Physiol C 138: $169-175$

Seckl JR (2001). Glucocorticoid programming of the fetus: adult phenotypes and molecular mechanisms. Mol Cell Endocrinol 185: $61-71$.

Shinwell ES, Karplus M, Reich D, Weintraub Z, Blazer S, Bader D et al (2000). Early postnatal dexamethasone treatment and increased incidence of cerebral palsy. Arch Dis Child 83: F177-F181.

Simon JR, Atweh S, Kuhar MJ (1976). Sodium-dependent high affinity choline uptake: a regulatory step in the synthesis of acetylcholine. J Neurochem 26: 909-922.

Slotkin TA (2005). Developmental neurotoxicity of organophosphates: a case study of chlorpyrifos. In: Gupta RC (ed). Toxicity of Organophosphate and Carbamate Pesticides. Elsevier: Amsterdam (in press).

Slotkin TA, Miller DB, Fumagalli F, McCook EC, Zhang J, Bissette $\mathrm{G}$ et al (1999). Modeling geriatric depression in animals: biochemical and behavioral effects of olfactory bulbectomy in young versus aged rats. J Pharmacol Exp Ther 289: 334-345.

Slotkin TA, Seidler FJ, Crain BJ, Bell JM, Bissette G, Nemeroff CB (1990). Regulatory changes in presynaptic cholinergic function assessed in rapid autopsy material from patients with Alzheimer disease: Implications for etiology and therapy. Proc Natl Acad Sci USA 87: 2452-2455.

Smith PK, Krohn RI, Hermanson GT, Mallia AK, Gartner FH, Provenzano MD et al (1985). Measurement of protein using bicinchoninic acid. Anal Biochem 150: 76-85.

Snedecor GW, Cochran WG (1967). Statistical Methods. Iowa State University Press: Ames, IA, 593pp.
Speirs HJ, Seckl JR, Brown RW (2004). Ontogeny of glucocorticoid receptor and 11 $\beta$-hydroxysteroid dehydrogenase type-1 gene expression identifies potential critical periods of glucocorticoid susceptibility during development. J Endocrinol 181: 105-116.

Takahashi LK, Goh CS (1998). Glucocorticoid facilitation of cholinergic development in the rat hippocampus. Neuroscience 83: 1145-1153.

Trautman PD, Meyer-Bahlburg HFL, Postelnek J, New MI (1995). Effects of early prenatal dexamethasone on the cognitive and behavioral development of young children: results of a pilot study. Psychoneuroendocrinology 20: 439-449.

Vickroy T, Roeske W, Yamamura H (1984). Sodium-dependent high-affinity binding of $\left[{ }^{3} \mathrm{H}\right]$ hemicholinium-3 in the rat brain: a potentially selective marker for presynaptic cholinergic sites. Life Sci 35: 2335-2343.

Ward I (1972). Prenatal stress feminizes and demasculinizes the behavior of males. Science 175: 82-84.

Weinstock M (2001). Alterations induced by gestational stress in brain morphology and behaviour of the offspring. Prog Neurobiol 65: 427-451.

Welberg LAM, Seckl JR (2001). Prenatal stress, glucocorticoids and the programming of the brain. J Neuroendocrinol 13: 113-128.

Yeh TF, Lin YJ, Lin HC, Huang CC, Hsieh WS, Lin CH et al (2004). Outcomes at school age after postnatal dexamethasone therapy for lung disease of prematurity. N Engl J Med 350: 1304-1313.

Zahalka EA, Seidler FJ, Lappi SE, McCook EC, Yanai J, Slotkin TA (1992). Deficits in development of central cholinergic pathways caused by fetal nicotine exposure: differential effects on choline acetyltransferase activity and $\left[{ }^{3} \mathrm{H}\right]$ hemicholinium-3 binding. Neurotoxicol Teratol 14: 375-382.

Zahalka E, Seidler FJ, Lappi SE, Yanai J, Slotkin TA (1993a). Differential development of cholinergic nerve terminal markers in rat brain regions: Implications for nerve terminal density, impulse activity and specific gene expression. Brain Res 601: 221-229.

Zahalka EA, Seidler FJ, Slotkin TA (1993b). Dexamethasone treatment in utero enhances neonatal cholinergic nerve terminal development in rat brain. Res Commun Chem Pathol Pharmacol 81: 191-198. 